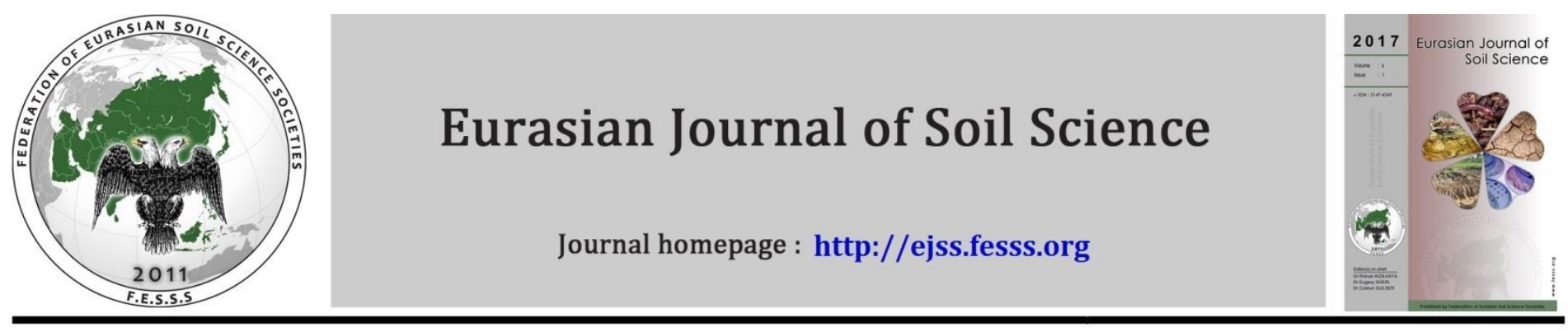

\title{
Fractal approach in characterization of spatial pattern of soil properties
}

\author{
Boško Miloš a, Aleksandra Bensa ${ }^{b, *}$ \\ ${ }^{a}$ Institute for Adriatic Crops and Karst Reclamation, Split, Croatia \\ b University of Zagreb, Faculty of Agriculture, Soil Science Department, Zagreb, Croatia
}

\section{Article Info}

Received : 16.03 .2016

Accepted : 23.05.2016

\begin{abstract}
The objective of the study was to characterize spatial pattern of soil properties $\left(\mathrm{CaCO}_{3}\right.$, soil organic carbon, $\mathrm{P}_{2} \mathrm{O}_{5}, \mathrm{~K}_{2} \mathrm{O}$, and clay content) using fractal concept. Total of 141 topsoil samples $(0-30 \mathrm{~cm})$ were collected on 1850 ha in karst polje (Petrovo polje, Croatia) and analyzed for listed soil properties. The semi-variogram method was used to estimate fractal dimension (D) value which was performed from both of isotropic and anisotropic perspective. The D value of soil properties ranged between 1.76 to 1.97, showing a domination of the short-range variations. The SOC and $\mathrm{K}_{2} \mathrm{O}$ fractal D values 1.79 and 1.76 respectively, exhibited a spatial continuity at the entire analysed range of the scale. The $\mathrm{D}$ value for $\mathrm{P}_{2} \mathrm{O}_{5}$ (1.97) showed a nearly total absence of the spatial structure at all scales. The $\mathrm{CaCO}_{3}$ and clay content indicated a multifractal behavior mainly attributed to effects of alluviation, differences in geology and its spatial changes and transitions. The results of anisotropic analysis of soil properties pattern have showed strong relations with directions and partial self-similarity over limited ranges of scales defined by scale-break. Finally, our results showed that fractal analysis can be used as a appropriate tool for the characterization of spatial pattern irregularities of soil properties and detection of soil forming factors that cause it.
\end{abstract}

Keywords: Fractal dimension, scale independency, self-similarity, semi-variogram.

(C) 2017 Federation of Eurasian Soil Science Societies. All rights reserved

\section{Introduction}

Spatial distribution of soil properties is strongly connected to soil forming factors and processes which operate over different spatial (and temporal) scales (Beckett and Webster 1971; Burrough, 1983a). The scale dependent nature of measurements and natural processes has been observed by many researchers (Burrough, 1981; Burrough, 1983a; Klinkenberg, 1992; Mark and Aronson, 1984; Peitgen and Saupe, 1988). Since the measurements are scale dependent the problem arises when representing the properties at the scale different from the one at which the measurements are made.

Fractal theory offers the possibility of analysing and quantifying soil variability measurements at different spatial scales. The term "fractal“ was introduced by Mandelbrot (1967), as a infinitely complex patterns that are self-similar across all spatial scales. Fractal (Hausdorff-Besicovitch) dimension (D) is generally a measurement of the irregularity of the object and a statistical indicator of the complexity of the fractal pattern that compares how the detail changes with scale. In fractal theory the concept of self-similarity means that fractal dimension (D) is a constant parameter at all scales implying that the form or pattern of the spatial phenomenon remains unchanged throughout all scales.

\footnotetext{
${ }^{*}$ Corresponding author.

University of Zagreb, Faculty of Agriculture, Soil Science Department, Svetošimunska 25, 10000 Zagreb, Croatia

Tel.: +38512393802

e-ISSN: $2147-4249$

E-mail address: abensa@agr.hr DOI: $10.18393 /$ ejss. 284260
} 
Numerous empirical studies have shown that this kind of true or mathematical fractals with strict selfsimilarity do not exist. Burrough (1981) has shown that many environmental variables are fractals and that the D values would be useful for separating scales of variation. The consequence is a variation of fractal dimension constant present only within specific ranges of scales. For this reason, natural features often show fractal self-similarity in many scales and a distinct fractal dimension for an each particular scale. Rather than using D in the strict sense Burrough (1981) suggested that Ma ndelbrot's D value can be used as an useful indicator of variation over many scales for natural phenomena. This phenomena (Burrough, 1983a; Klinkenberg and Goodchild, 1992) can be explained by a large number of various natural independent processes operating at own discrete scales separated by distinct scale breaks. Fractal dimension of landforms and linear natural phenomena are typically in the range of 1.1-1.3 (Mandelbrot, 1977), indicating domination of large-scale factors.

The fractal dimension (D) of a curve is a continuous function with range 1 to 2 . $D=1$ implies a continous curve, while $\mathrm{D}=2$ signifies a curve so "noisy“ and complex that it effectively takes up the whole of a twodimensional space. Large $D$ values (close to 2 ) indicate the importance of short-range variation, while small $D$ values reflect the importance of long-range variation (Burrough, 1981; Burrough, 1983a). Fractal dimensions of soils usually have a much higher proportion of short-range variation then other environmental variables (Burrough, 1981; Culling and Datko, 1987; Burrough, 1983a; Burrough, 1984). Fractal D values of soil properties almost always exceed 1.5, and many are greater than 1.8 (Burrough, 1981), suggesting that short-range effects prevail over long-range ones.

Many researchers (e.g. Burrough, 1981; Burrough, 1983a; Burrough, 1983b; Armstrong, 1986; Culling, 1986; Anderson et al., 1998; Bartoli et al, 1995) used fractal dimension (D) as a measure of relative ratio between short-range and long-range sources of variation.

In this study we calculated fractal dimension (D) for analysed soil properties for maximum point-pair distances and for linear portion of experimental log-log variogram defined with scale break. The objectives of the study were to establish fractal dimensions of the next soil properties: $\mathrm{CaCO}_{3}, \mathrm{SOC}, \mathrm{P}_{2} \mathrm{O}_{5}, \mathrm{~K}_{2} \mathrm{O}$, and clay content and characterize its spatial pattern.

\section{Material and Methods}

\section{Study area}

The study area is located in Petrovo polje in the middle Dalmatia, Croatia, centred on $43^{\circ} 51^{\prime} 05^{\prime \prime} \mathrm{N} ; 6^{\circ} 12^{\prime} 45^{\prime \prime}$ W (Figure 1). The climate of the researched location belongs to Mediterranean temperate humid climate with hot summer. Hydrology of this typical karst polje is characterized by excessive wetting and occasional flooding in wet period of the year and water deficit in hot season. Petrovo polje is a large flat depression with a slope $0-^{\circ}$ (slopes $<0.5^{\circ}$ prevail), and intersected by the Čikola river and its tributary torrent Mahnitaš. Alluvial sediments cover most of the area (Ivanović et al., 1972), with occasional interbeds of Permian volcanic rocks (spilite and diabase) and Permian/Triassic clastic sediments (sandstones and breccias). The variety of soil forming factors and processes and their complex interactions resulted in a great diversity of soil types in Petrovo polje (Miloš, 1987). Investigated soils are identified as Calcaric Gleyic Fluvisols (Loamic) and Mollic Eutric Gleysols (Clayic, Humic, Vertic), (IUSS Working Group WRB, 2014). Study area is dominated by complex cultivation patterns (ploughed land, meadows and pastures) and vineyards.

\section{Soil data set and laboratory analyses}

Total of 141 top-soil samples $(0-30 \mathrm{~cm})$ were collected on the area of 1850 ha using grid sampling scheme with distance of $350 \mathrm{~m}$. Soil samples were analysed by following methods: SOC content (Kotzman method, JDPZa, 1966), total carbonates content (Scheibler method, JDPZa, 1966), available phosphorus and potassium content (AL method, JDPZa, 1966) and soil particle size distribution (International B pipette method, JDPZb, 1966).

\section{Measurement of fractal dimension}

The variogram method was used in the estimation of fractal dimension $(D)$. The semivariance is defined by equation:

$$
\gamma(\mathrm{h})=\frac{1}{2 N(h)} \sum_{i=1}^{N(h)}\left(Z_{x+h}-Z_{x}\right)^{2}
$$


where, $\mathrm{h}$ is the lag distance (distance between succesive points), $\gamma(\mathrm{h})$ is the semivariance at lag distance „h“, $Z_{(x)}$ and $Z_{(x+h)}$ - values of the variable at location $x_{i}$ and $x_{i+h}$, respectively and $N(h)$ is the number of pairs considered.

Fractal distributions are characterized by a variogram model of the following form:

$$
2 \gamma_{\mathrm{h}}=\mathrm{h}^{\beta}
$$

where, $D=2-\beta / 2$ (Hausdorff-Besicovitch statistic - fractal dimension, $\beta=4-2 D$ (the slope of the log-log plot variogram).

Fractal dimensions were calculated for the isotropic and anisotropic perspectives for four main directions of h $\left(0^{\circ}: \mathrm{N}-\mathrm{S}, 45^{\circ}: \mathrm{NE}-\mathrm{SW}, 90^{\circ}: \mathrm{E}-\mathrm{W}\right.$ and $\left.135^{\circ}: \mathrm{SE}-\mathrm{NW}\right)$ which were set with an angular tolerance of $22.5^{\circ}$.

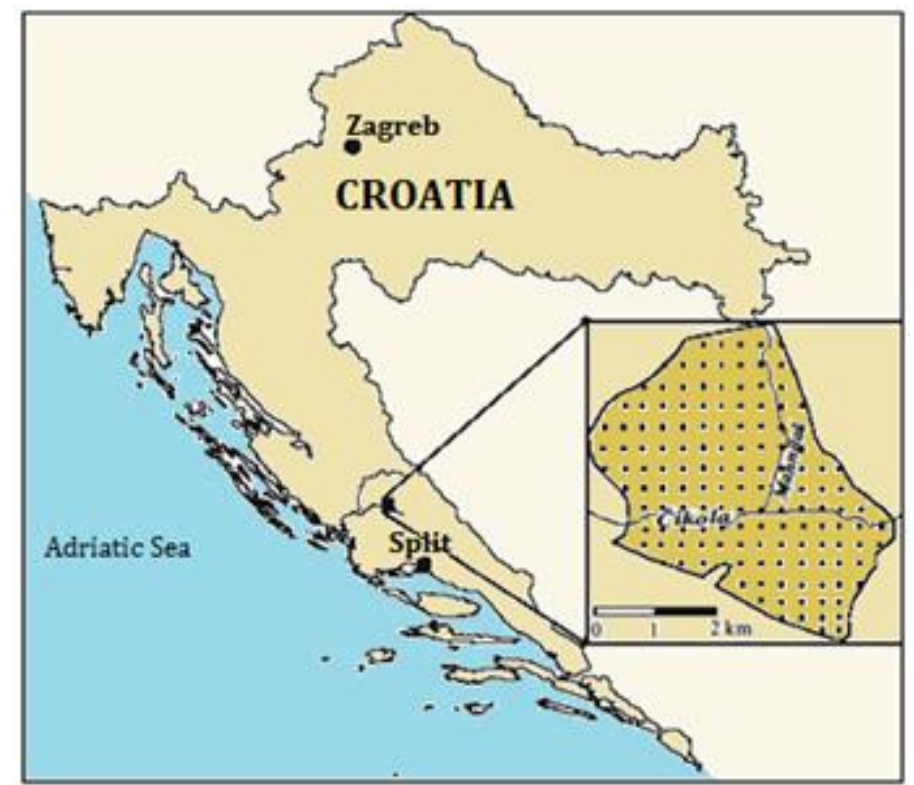

Figure 1. Location of the study area and sampling points

\section{Determination of scale breaks}

The fractal dimension was estimated from a slope of log-log variogram. The changes of the slope are continuously from one linear segment to another. When break in the slope of the double log variogram plot was observed the break distance or scale-break was determined, as the distance within which the log-log variogram can be fitted by a line provided that the coefficient of determination as a goodness-of-fit measure $\mathrm{R}^{2}>0.90$ (Klinkenberg, 1992). The next requirement for determining the break distance was minimum of 100 point pairs at a distance with goodness-of-fit measure $\mathrm{R}^{2}>0.90$. The additional fractal parameter was gamma $(\gamma)$ defined as the intercept of the best-fitting line with the ordinate (Klinkenberg and Goodchild, 1992).

\section{Results and Discussion}

\section{Descriptive statistics of the soil properties}

Statistical parameters of the top-soil horizon attributes of Petrovo polje are given in Table 1 . The $\mathrm{CaCO}_{3}$ content has a wide range, a high coefficient of variation (CV) and slightly right-skewed distribution with a more rounded peak near the mean with shorter thinner tails. The wide range of $\mathrm{CaCO}_{3}$ is caused by great differences in geology and characteristics of alluvial deposits. Due to this soils vary from non-calcareous to strongly calcareous, in average are moderately calcareous. The top-soil SOC content varies from very low to medium, in average is low. The distribution of SOC content is asymmetrically, highly right skewed with a long tail to the right. Positive kurtosis indicates a sharper peak around the mean with longer, fatter tails. The clay content is characterized with a high mean value, wide range, low coefficient of the variation and near normal distribution. The variation of clay content is related to differences in parent material and alluviation.

The mean $\mathrm{P}_{2} \mathrm{O}_{5}$ and $\mathrm{K}_{2} \mathrm{O}$ content show that the top-soil horizon is very low supplied with available phosphorus and sufficient with available potassium. The $\mathrm{P}_{2} \mathrm{O}_{5}$ content has high coefficient of variation and substantially right-skewed distribution with a long tail to the right and high peak around the mean with longer, fatter tails. The $\mathrm{K}_{2} \mathrm{O}$ content has a lower coefficient of variation and considerably weaker expressed asymmetry than $\mathrm{P}_{2} \mathrm{O}_{5}$. 
Table 1. Descriptive statistics for $\mathrm{CaCO}_{3}, \mathrm{SOC}, \mathrm{K}_{2} \mathrm{O}_{2} \mathrm{P}_{2} \mathrm{O}_{5}$ and clay content

\begin{tabular}{lccccccc}
\hline Property & Mean & Min. & Max. & "S.D. & ${ }^{\text {\&CV } \%}$ & Skewness & Kurtosis \\
\hline $\mathrm{CaCO}_{3}(\%)$ & 16.66 & 0.00 & 53.30 & 13.74 & 82.5 & 0.45 & -0.91 \\
$\mathrm{SOC}\left(\mathrm{g} \mathrm{C} \mathrm{kg}^{-1}\right.$ ) & 19.26 & 9.88 & 49.59 & 7.09 & 36.8 & 1.16 & 1.85 \\
$\mathrm{Clay}<0.002 \mathrm{~mm}(\%)$ & 38.95 & 24.70 & 6.60 & 8.60 & 22.1 & 0.40 & -0.39 \\
$\mathrm{~K}_{2} \mathrm{O} \mathrm{mg} / 100 \mathrm{~g}$ & 21.10 & 5.50 & 55.60 & 8.99 & 42.6 & 0.94 & 0.84 \\
$\mathrm{P}_{2} \mathrm{O}_{5} \mathrm{mg} / 100 \mathrm{~g}$ & 2.81 & 0.10 & 10.50 & 2.32 & 82.7 & 1.52 & 1.78 \\
\hline
\end{tabular}

"S.D., standard deviation. ${ }^{\&} \mathrm{CV}(\%)$, coefficient of variation (\%).

\section{Fractal parameters of the soil properties}

Estimated log-log variograms of the soil properties (Figure 2 and Figure 3) are complex functions characterized with different forms. We recognized a few fractal log-log plot forms. The SOC and, in particular, $\mathrm{K}_{2} \mathrm{O}$ log-log isotropic variogram forms show small discontinuity at origin and gradually oscillating increase with separation with distance at all scale. These variogram shapes show a spatial continuity at the entire analysed range of the scale. The high D values of $1.76\left(\mathrm{~K}_{2} \mathrm{O}\right)$ and 1.79 (SOC) indicate dominance of short-range effects of spatial variations (Table 2). The results of anisotropic analyses for SOC indicate a low spatial continuity (domination of irregular and largely uncorrelated variations) for all directions except $\mathrm{N}-\mathrm{S}$, which shows elements of a slight smoothly variation (Figure $2 b$ and Table 2). This spatial structure is probably related to the alluviation and topography position which are the most obviously changing in this direction.

The results of anisotropic analyses for $\mathrm{K}_{2} \mathrm{O}$ show how its self-simarity varies with direction (Figure $2 \mathrm{~d}$ and Table 2). The higher $\mathrm{R}^{2}$, lower intercept gamma $(\gamma)$ and standard error (SE) and, consequently lower $\mathrm{D}$ value have SE-NW and E-W directions. This indicates the presence of smoothly variations of $\mathrm{K}_{2} \mathrm{O}$ in these directions. These directions correspond to the direction of the most distinctive changes of intensity of fertilization.

The log-log isotropic variogram plot for $\mathrm{P}_{2} \mathrm{O}_{5}$ (Figure 2e) shows a great discontinuity at origin and irregular form that effectively takes up the whole of a two-dimensional topological space. This form approximated by a straight line is characterized with great intercept gamma $(\gamma)$, small slope of the regression line, very high standard error and consequently a very high fractal D value (Table 2). These results show dominance of ultra short-range effects spatial variation indicating an almost totally random data and nearly absence of the spatial structure. Very high fractal $D$ values for soil phosforus $(D=2.0)$ and lower $D$ for soil potassium $(D=1.6)$ found Burrough (1981) using data from earlier soil research of Webster and Butler (1976).

Table 2. The fractal dimension (D), gamma $(\gamma)$, coefficient of determination $\left(\mathrm{R}^{2}\right)$ and standard error (SE) of soil organic carbon (SOC), $\mathrm{K}_{2} \mathrm{O}$ and $\mathrm{P}_{2} \mathrm{O}_{5}$ for isotropic and anisotropic perspective

\begin{tabular}{ccccccc}
\hline Soil & Statistic & \multicolumn{3}{c}{ Isotropic } & \multicolumn{3}{c}{ Anisotropic (All lag h) } \\
\cline { 3 - 7 } property & parameters & All lag h & N-S & NE-SW & E-W & SE-NW \\
\hline \multirow{2}{*}{ SOC } & D & 1.79 & 1.76 & 1.82 & 1.84 & 1.81 \\
$\mathrm{C} \mathrm{g} \mathrm{kg}^{-1}$ & gamma $(\gamma)$ & 0.28 & 0.09 & 0.40 & 0.31 & 0.62 \\
& $\mathrm{R}^{2}$ & 0.92 & 0.91 & 0.53 & 0.68 & 0.84 \\
& $\mathrm{SE}$ & 0.138 & 0.14 & 0.43 & 0.32 & 0.22 \\
\hline & $\mathrm{D}$ & 1.76 & 1.82 & 1.89 & 1.70 & 1.66 \\
$\mathrm{~K}_{2} \mathrm{O}$ & gamma $(\gamma)$ & 0.26 & 0.51 & 1.02 & -0.12 & -0.31 \\
$\mathrm{mg} / 100 \mathrm{~g}$ & $\mathrm{R}^{2}$ & 0.89 & 0.51 & 0.27 & 0.81 & 0.97 \\
& $\mathrm{SE}$ & 0.19 & 0.39 & 0.86 & 0.21 & 0.07 \\
\hline & $\mathrm{D}$ & 1.97 & 1.86 & 1.98 & 1.84 & 1.90 \\
$\mathrm{P}_{2} \mathrm{O}_{5}$ & gamma $(\gamma)$ & 0.35 & 1.33 & 0.49 & -0.19 & -0.16 \\
$\mathrm{mg} / 100 \mathrm{~g}$ & $\mathrm{R}$ & 0.23 & -0.64 & 0.02 & 0.88 & 0.83 \\
& $\mathrm{SE}$ & 0.86 & 0.36 & 3.73 & 0.18 & 0.22 \\
\hline
\end{tabular}

The anisotropic log-log variogram shapes for $\mathrm{P}_{2} \mathrm{O}_{5}$ indicate almost totaly absence of the spatial structure in the N-S and NE-SW directions (Table 2 and Figure 2f). Contrary, $\mathrm{P}_{2} \mathrm{O}_{5} \log$-log shapes appear to be homogeneous in the E-W and SE-NW directions. It is interesting to note that $\mathrm{P}_{2} \mathrm{O}_{5}$ as well as $\mathrm{K}_{2} \mathrm{O}$ shows the 
highest self-similarity in E-W and SE-NW directions in which anthropogenic impact (fertilization) is the most intense changing.
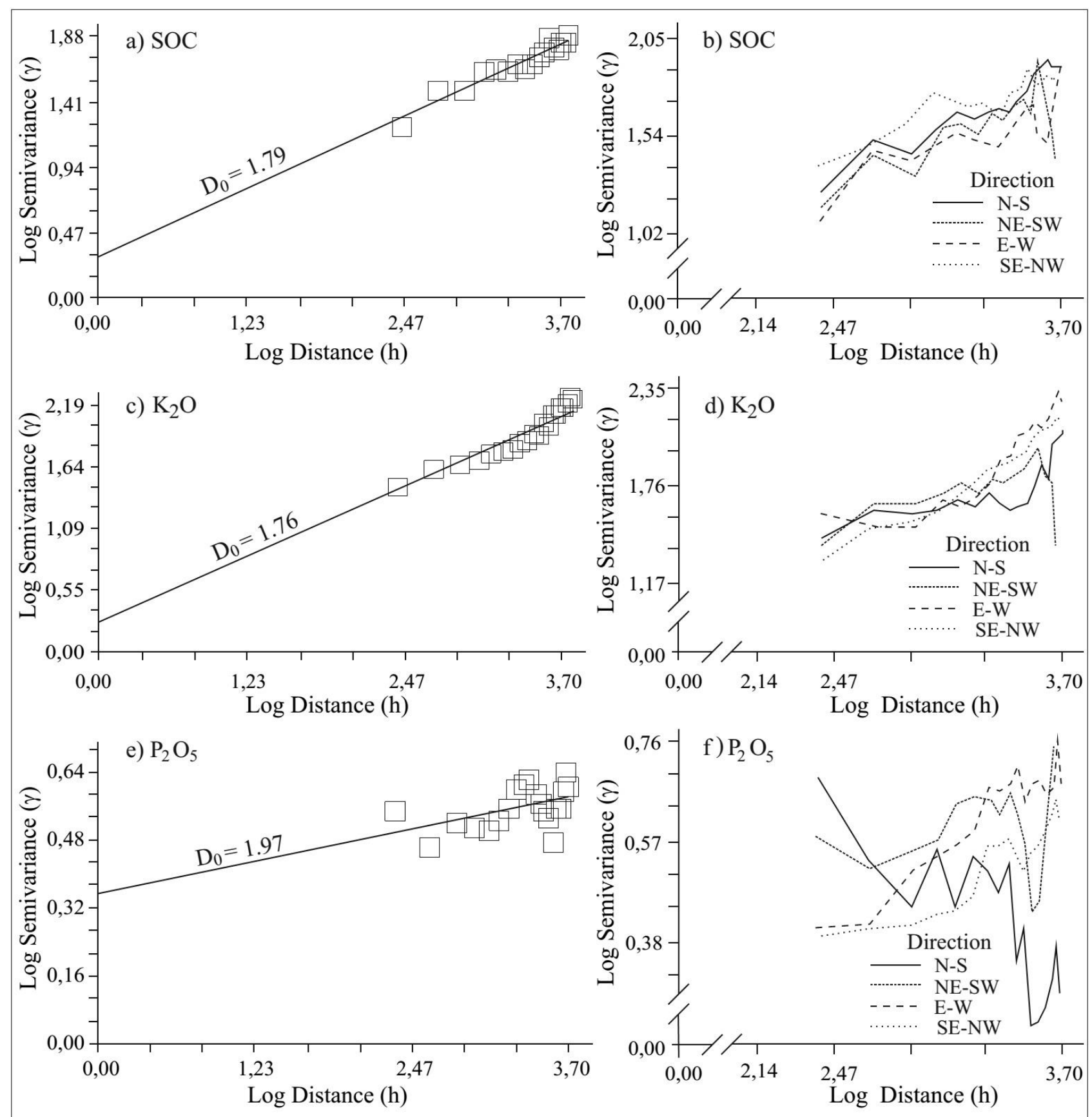

Figure 2. Log-log plot of isotropic variograms with fractal dimension $\left(\mathrm{D}_{0}\right)$ for $\mathrm{SOC}(\mathrm{a}), \mathrm{K}_{2} \mathrm{O}(\mathrm{c}), \mathrm{P}_{2} \mathrm{O}_{5}(\mathrm{e})$; anisotropic variograms for SOC (b), $\mathrm{K}_{2} \mathrm{O}$ (d), $\mathrm{P}_{2} \mathrm{O}_{5}$ (f) for four main directions of $\mathrm{h}(\mathrm{N}-\mathrm{S}, \mathrm{NE}-\mathrm{SW}, \mathrm{E}-\mathrm{W}$ and SE-NW)

The fractal parameters for $\mathrm{CaCO}_{3}$ and clay content are performed from both an isotropic and anisotropic perspective (Figure 3 and Table 3). The double log isotropic variograms show a great discontinuity at origin, non-monotonic increase with separation and having achieved sill, then it decreases (Figure 3a and 3c). Approximation of this variogram forms with straight line resulted in a low coefficient of determination $\left(\mathrm{R}^{2}\right)$, the high associated SE and consequently high fractal D value (Table 3). Burrough (1981) has found similar high fractal dimension $(D=1.8)$ for top-soil silt + clay at $1 \mathrm{~km}$ lag distance. The soil properties often exhibit a great spatial variation at short distances. The high variability at short distance of soil properties has been reported in many studies (Becket and Webster, 1971; Webster and Butler, 1976; Burgess and Webster, 1980; McBratney and Webster, 1981; Burrough, 1983a). The high dicontinuity of the soil properties at origin and its often highly dependence on sampling directions are in accordance with previous geostatistical research of the soil variability in Petrovo polje (Miloš, 2000). 

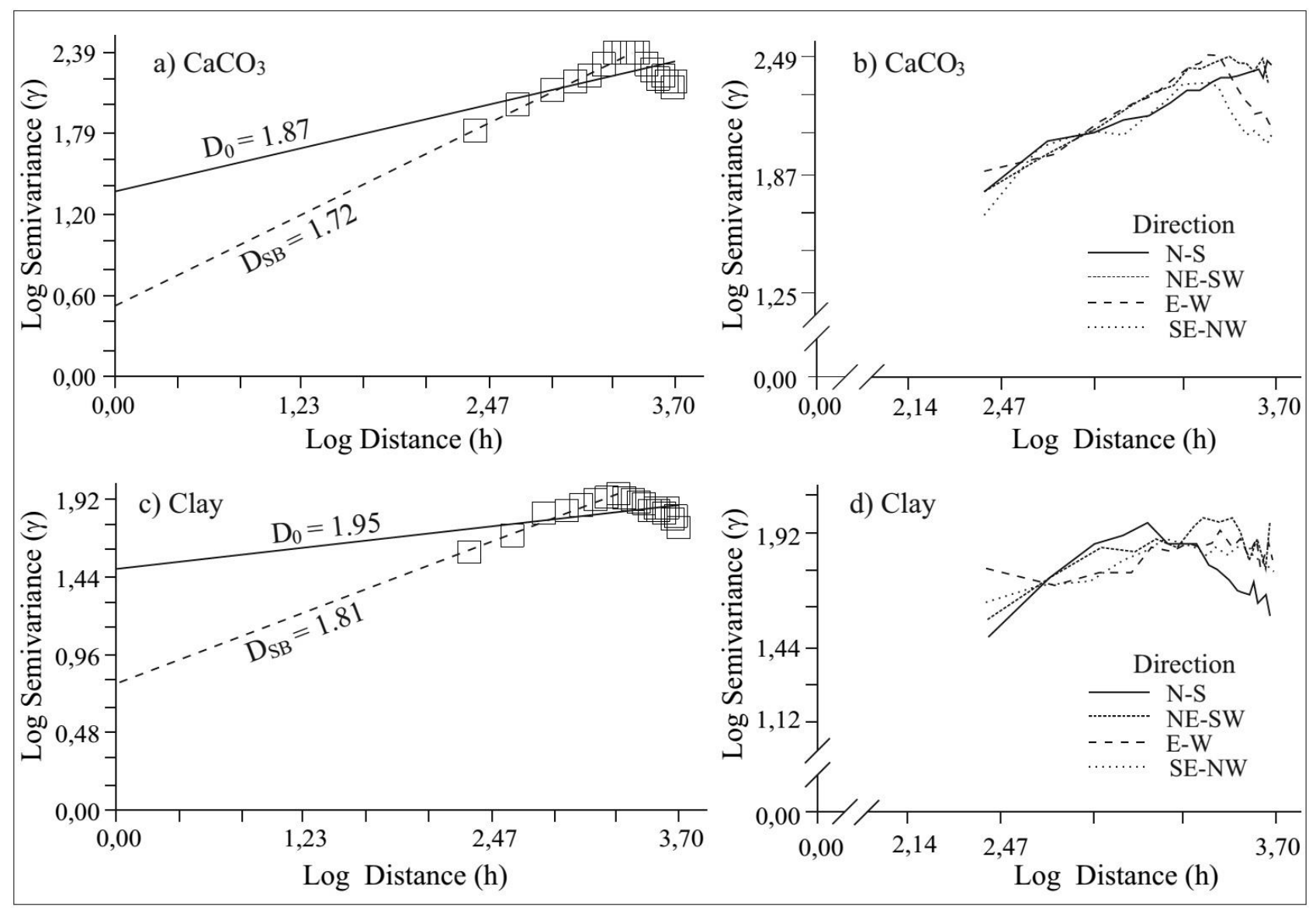

Figure 3. Log-log plot of isotropic variogram with fractal dimension $\left(D_{0}\right)$ of the regression line for the all lag $h ; D_{S B}-$

fractal dimension of the first regression segment separated with the scale-break for $\mathrm{CaCO}_{3}(\mathrm{a})$ and clay content (c); anisotropic variograms for $\mathrm{CaCO}_{3}$ (b) and clay content (d) for four main directions of h (N-S, NE-SW, E-W and SE-NW)

Table 3. The fractal dimension (D), gamma $(\gamma)$, coefficient of determination $\left(\mathrm{R}^{2}\right)$, standard error (SE) and scale-break (SB) for $\mathrm{CaCO}_{3}$ and clay content for isotropic and anisotropic perspective

\begin{tabular}{|c|c|c|c|c|c|c|c|}
\hline \multirow{2}{*}{$\begin{array}{c}\text { Soil } \\
\text { property }\end{array}$} & \multirow{2}{*}{$\begin{array}{c}\text { Statistic } \\
\text { parameters }\end{array}$} & \multicolumn{3}{|c|}{ Isotropic } & \multicolumn{3}{|c|}{ Anisotropic (All lag h) } \\
\hline & & All lag $\mathrm{h}$ & Scale-break & $\mathrm{N}-\mathrm{S}$ & NE-SW & E-W & SE-NW \\
\hline \multirow{5}{*}{$\mathrm{CaCO}_{3}(\%)$} & $\mathrm{D}$ & 1,87 & 1.72 & 1.76 & 1.73 & 1.90 & 1.89 \\
\hline & $\operatorname{gamma}(\gamma)$ & 1.36 & 0.53 & 0.59 & 0.54 & 1.53 & 1.42 \\
\hline & $\mathrm{R}^{2}$ & 0.40 & 0.98 & 0.97 & 0.90 & 0.22 & 0.24 \\
\hline & SE & 0.59 & 0.06 & 0.09 & 0.16 & 0.93 & 0.87 \\
\hline & $\mathrm{SB}(\mathrm{m})$ & - & 3150 & 5250 & 3500 & 3150 & 2800 \\
\hline \multirow{5}{*}{$\begin{array}{c}\text { Clay }<0.002 \mathrm{~mm} \\
(\%)\end{array}$} & $\mathrm{D}$ & 1,95 & 1.81 & 1.98 & 1.89 & 1.95 & 1.94 \\
\hline & gamma $(\gamma)$ & 1.51 & 0.77 & 1.93 & 1.20 & 1.49 & 1.42 \\
\hline & $\mathrm{R}^{2}$ & 0.21 & 0.93 & 0.01 & 0.48 & 0.42 & 0.40 \\
\hline & SE & 0.98 & 0.21 & 4.69 & 0.54 & 0.60 & 0.62 \\
\hline & $\mathrm{SB}(\mathrm{m})$ & - & 2450 & 1750 & 2800 & 3500 & 2100 \\
\hline
\end{tabular}

The $\mathrm{CaCO}_{3}$ and clay content showed a multifractal behavior in the isotropic and anisotropic perspective characterized with hole effect and partial self-similarity over limited ranges of scales defined by scale-break (Figure 3). Over the analyzed scale of $5250 \mathrm{~m}$ we found a scale break at the distance of $3150 \mathrm{~m}$ for the $\mathrm{CaCO}_{3}$ and $2450 \mathrm{~m}$ for the clay content for isotropic perspective. These results show that $\mathrm{CaCO}_{3}$ and clay content point values are scale independent or self-similar over the scale of $3150 \mathrm{~m}$ and $2450 \mathrm{~m}$, respectively. An estimated very high D values indicated high proportion of short-range variation and the closeness of scales of variation of factors that can cause abrupt transitions (Figure 3a and Figure 3c and Table 3). These results are consistent with research of Burrough (1981 and 1983a) and Culling (1986) who reported on the high fractal values of the individual properties of the soil. 
The results of anisotropic analysis for $\mathrm{CaCO}_{3}$ and clay content show strong effect of direction on the distance within which its values are spatially correlated. In the N-S direction $\mathrm{CaCO}_{3}$ content is scale independent at all lag h $(5250 \mathrm{~m})$. Other three main directions have shorter break-distance and a higher D values (Table 3 and Figure $3 b)$.

The anisotropic analysis of clay content shows domination of short-range variations and strong relations between directions and its spatial continuity. The double log variogram shape for N-S (Figure 3d), as well as $\mathrm{E}-\mathrm{W}$ and SE-NW directions for $\mathrm{CaCO}_{3}$ (Figure 3b) exhibit the hole effect indicating a multifractal behavior that is mainly attributed to effects of various soil-forming factors which operate simultaneously at different scales. Estimated fractal parameters (Table 3) indicated high proportion of short-range variations and the closeness of scales of variations of factors that can cause abrupt transitions.

The causes of high fractal D values of analysed soil properties and consequently a short-range effect are numerous. The spatial pattern of $\mathrm{CaCO}_{3}$ and clay content are mainly attributed to effects of various soilforming factors and processes, first of all, by alluviation, differences in geology and its spatial changes and transitions.

In order to compare our results to classical geostatistical approach we conducted (semi)variogram analysis. The parameters of experimental semivariograms: nugget (discontinuity at the origin), sill (structured variance), nugget/sill ratio (nugget effect), range (lag distance at which the semivariogram reaches the sill value) and fitted models were calculated for isotropic perspective (Table 4). The $\mathrm{K}_{2} \mathrm{O}$ and SOC content are the best fitted with Gaussian and Exponential model and characterized with small nugget effects of $15.0 \%$ and $19.3 \%$, respectively. The ranges for these models ( $9650 \mathrm{~m}$ for $\mathrm{K}_{2} \mathrm{O}$ and $9050 \mathrm{~m}$ for SOC) exhibited a spatial continuity at the entire analysed scale. The experimental semivariograms for $\mathrm{CaCO}_{3}$ and clay content are fitted with spherical model and characterized with shorter range than distance of the analyzed scale $(5250 \mathrm{~m})$. The nugget effect represents $25.6 \%$ of the spatial variation for $\mathrm{CaCO}_{3}$ and $32.3 \%$ for clay content. The $\mathrm{P}_{2} \mathrm{O}_{5}$ semivariogram have a great nugget effect (42.5\%) and range smaller than the sampling interval. Comparison of estimated nugget effects and ranges in Table 4 shows that higher nugget effect imply shorter range.

Table 4. Geostatistical parameters of experimental semivariogram for soil properties

\begin{tabular}{|c|c|c|c|c|c|}
\hline Soil property & $\begin{array}{c}\text { Nugget } \\
\text { (Co) }\end{array}$ & $\begin{array}{c}\text { Sill } \\
(\mathrm{Co}+\mathrm{C})\end{array}$ & $\begin{array}{c}\text { Nugget/sill ratio } \\
\text { Co/(Co+C) x } 100 \\
(\%)\end{array}$ & $\begin{array}{c}\text { Range } \\
\text { (m) }\end{array}$ & Model \\
\hline $\mathrm{CaCO}_{3}(\%)$ & 48.3 & 188.9 & 25.6 & 2150 & Spherical \\
\hline $\operatorname{SOC}\left(\mathrm{g} \mathrm{C} \mathrm{kg}^{-1}\right)$ & 16.5 & 85.35 & 19.3 & 9050 & Exponential \\
\hline Clay $<0.002$ mm (\%) & 23.3 & 72.17 & 32.3 & 1250 & Spherical \\
\hline $\mathrm{K}_{2} \mathrm{O}, \mathrm{mg} / 100 \mathrm{~g}$ & 37.6 & 250.5 & 15.0 & 9650 & Gaussian \\
\hline $\mathrm{P}_{2} \mathrm{O}_{5}, \mathrm{mg} / 100 \mathrm{~g}$ & 1.55 & 3.65 & 42.5 & 100 & Gaussian \\
\hline
\end{tabular}

By comparing the results of variogram analysis and fractal approach, especially in term of range variation, we can see agreement in the fitted ranges of the experimental semivariograms and ranges defined with scale break for all selected soil properties.

Our results showed that fractal approach can provide appropriate tool for the characterization of spatial pattern irregularities of soil properties and identification of soil forming factors that drive spatial heterogeneity.

\section{References}

Armstrong, A.C., 1986. On the fractal dimensions of some transient soil properties. European Journal of Soil Science 37(4): 641-652.

Anderson, A.N., McBratney, A.B., Crawford, J.W., 1998. Applications of fractals to soil studies. In: Sparks, D.L. (Ed.). Advances in Agronomy. Vol. 63. Academic Press, New York, pp.1-76.

Bartoli F., Burtin G., Royer J.J., Gury M., Gomendy, V., Philippy, R., Leviandier, Th., Gafrej, R., 1995. Spatial variability of topsoil characteristic within one silty soil type. Effect of clay migration. Geoderma 68(4): 279-300.

Beckett, P.H.T., Webster. R., 1971. Soil variability: A review. Soils and Fertilizers 34: 1-15

Burgess, T.M., Webster, R., 1980. Optimal interpolation and isarithmic mapping of soil properties. I. Semivariogram and punctual kriging. II. Block kriging. European Journal of Soil Science 31(2): 315-342.

Burrough, P.A., 1981. Fractal dimensions of landscapes and other environmental data. Nature 294: 240-242. 
Burrough, P.A., 1983a. Multiscale sources of spatial variation in soil. I. The application of fractal concepts to nested levels of soil variation. European Journal of Soil Science 34(3): 577-597.

Burrough, P. A., 1983b. Multiscale sources of spatial variation in soil. II. A non- brownian fractal model and its application in soil survey. European Journal of Soil Science 34(3): 599-620.

Burrough, P.A., 1984. The application of fractal ideas to geophysical phenomena. Bulletin of the Institute of Mathematics and its Application 20: 36-42

Culling, W.E.H., 1986. Highly erratic spatial variability of soil-pH on Iping Common, West Sussex. Catena 13(1-2): 81-98.

Culling, W.E.H. and Datko M.,1987. The fractal geometry of the soil-covered landscape. Earth Surface Processes and Landforms 12 (4): 369-385.

IUSS Working Group WRB, 2014. World reference base for soil resources 2014. World Soil Resources Reports No. 106, FAO, Rome, Italy.

Ivanović, A., Sikirica, V., Marković, S.. Sakač, K., 1972. Bacic geological map of SFRJ, Drniš K 33-9, M=1:100 000. Institute for geological investigations, Beograd [in Croatian].

JDPZa, 1966. Chemical methods for soil analysis, Beograd [in Croatian].

JDPZb, 1966. Physical methods for soil analysis, Beograd [in Croatian].

Klinkenberg, B., 1992, Fractals and morphometric measures: Is there a relationship? Geomorphology 5(1-2): 5-20.

Klinkenberg, B., Goodchild, M.F., 1992. The fractal properties of topography: a comparison of methods. Earth Surface Processes and Landforms 17 (3): 217-234.

Mandelbrot, B., B., 1967. How long is the coast of britain? Statistical self-similarity and fractional dimension. Science 156: 636-638.

Mandelbrot, B., B., 1977. Fractals: Form, Chance and Dimension. Freeman, London

Mark, D.M., Aronson, P.B., 1984. Scale-dependent fractal dimensions of topographic surfaces: an empirical investigation, with applications in geomorphology and computer mapping. Journal of the International Association for Mathematical Geology 16 (7): 671-683.

McBratney, A.B., Webster, R., 1981. Spatial dependence and classification of the soil along a transect in North-east Scotland. Geoderma 26(1-2), 63-82.

Miloš, B., 1987. Numerical classification of hydromorphic soils, PhD thesis, Faculty of Forestry University of Sarajevo, Sarajevo, Bosnia and Herzegovina [in Croatian].

Miloš, B., 2000. Geostatistical soil data analysis. I. Measuring spatial variability of soil properties with semivariograms. Agriculturae Conspectus Scientificus 65(4): 219-228.

Peitgen H.O., Saupe D., 1988. The science of fractal images. Springer-Verlag, New York, USA.

Webster, R., Butler, B., 1976. Soil classification and survey studies at Ginninderra. Australian Journal of Soil Research 14(1): 1-24. 